\title{
Learning in Global Teams: BIM Planning and Coordination
}

\section{Carrie Sturts Dossick ${ }^{1}{ }^{*}$, Hoda Homayouni1 ${ }^{1}$ and Ghang Lee ${ }^{2}$}

${ }^{1}$ College of Built Environments, University of Washington, America

${ }^{2}$ Department of Architectural Engineering, Yonsei University, Korea

(Received 20 April 2015; Accept 14 July 2015; Published on line 1 September 2015)

*Corresponding author mail: cdossick@uw.edu

DOI: 10.5875 /ausmt.v5i3.916

\begin{abstract}
Globally distributed student team projects allow for complex and multifaceted learning outcomes through experiential educational settings. While the students involved may be studying built environment disciplines such as architecture, engineering and construction, distributed teams are mediated by technology, separated by time zones, and differentiated by culture. In this paper, we explore such multifaceted learning in a globally distributed team project where students from seven universities on three continents participated in a 2-week global team workshop to study rapid construction for disaster response. The participating schools included the Indian Institute of Technology Madras (IIT), National Cheng Kung University (NCKU), National Taiwan University (NTU), the University of Twente (UT), the University of Washington (UW), Washington State University (WSU), and Yonsei University (YU). For the term project students collaborated and coordinated their work in a virtual world. Upon project completion, we conducted a survey with students from two of the participating universities and analyzed their reflections as reported in their final presentations. We found that the distributed nature of the teams emphasized the importance of Building Information Modeling (BIM) execution planning and its joint development as well as the importance of shared project goals and early involvement of team members in the planning process.
\end{abstract}

Keywords: Global teams; BIM execution planning; BIM education

\section{Introduction}

Building Information Modeling (BIM) has been touted as a collaboration method that facilitates collaboration among practitioners from various disciplines [1]. Such collaborative support is crucial to the success of globally distributed teams working on separate scopes in different time zones and often with different conceptual understandings of the task at hand. As the industry moves towards distributed work[2], students in architecture, engineering and construction (AEC) need to develop skills required by distributed team environments, including technological fluency as well as collaboration leadership and management.

This paper explores teaching and learning about global virtual teamwork and the multifaceted learning outcomes that these experiential learning settings provide.
In this project we used BIM planning techniques to formalize learning about collaboration as well as the technologies used by students to execute distributed work. In the hands-on exercises analyzed here, students experienced the challenges of collaborating effectively on design and construction planning projects when their design and construction planning partners were distributed across different universities and different countries. This study builds on previous collaborative virtual design team research (e.g., CyberGRID Networks: Cyber-enabled Global Research Infrastructure for Design Network)[3][4].

The learning objectives of this project span a variety of outcome goals including leadership, management competence, and technology mastery, as well as applied design and construction expertise. First, we want the students to learn leadership and management skills related to distributed project management such as task 
planning and team building. Distributed AEC teams are challenged to exchange information in meaningful and coordinated ways and to develop novel solutions through distributed collaboration[5]. It has been shown that experience working in distributed teams improves team member engagement and performance as students acquire the skills to bridge the physical, cultural and language divides between individuals, organizations and countries[4]. The first learning goal of this educational project is to develop distributed team leadership and management skills.

The second goal was for students to gain an understanding of BIM tools for design review, construction sequence planning and cost estimating. In addition, we wanted to expose them to virtual team tool functionalities such as Voice over IP, screen sharing, chat,

Carrie Sturts Dossick is the Director for the Pacific Northwest Center for Construction Research and Education, an Associate Professor in the Department of Construction Management in the College of Built Environments at the University of Washington. Dr. Dossick's research interests include data practices, collaboration, technologies and building information modeling (BIM). Current projects include (1) technology and collaboration strategies for green building design and construction, (2) Global virtual teams, (3) applications of BIM and COBie in building operations funded by the University of Washington and Sound Transit (4) Integrated Project Delivery. She has received funding from the National Science Foundation, U.S. Army, U.S. Department of Education, Hewlett Packard Skanska Building USA, University of Washington Royalty Research Fund, the College of Built Environments' BE Lab and was awarded the College of Architecture and Urban Planning 2007 Dean's Development Award. In 2005 she was awarded the ASCE 2005 Best Peer Reviewed Paper of the Year for her work on Pricing Engineering Services, and more recently the Best pape award from the Engineering Project Organization Society for her work on Building Information Modeling.

Carrie Sturts Dossick < cdossick@u.washington.edu $>$

Hoda Homayouni is a researcher in architecture and construction management discipline. She holds a Bachelor of Science degree in Architectural Engineering from University of Tehran, a Master of Science in Design Computing, and a Doctorate of Philosophy in the Built Environments from University of Washington. Her scholarly work includes studies on computational approaches to architectural design process, organizational approaches to design and construction of High Performance buildings, as well as educational approaches to new technologies and global collaborative practices in schools of architecture and project management. Hoda Homayouni <hoda@uw.edu $>$

Ghang Lee is Associate Professor and Director of the Building Informatics Group (BIG) at the Department of Architectural Engineering at Yonsei University in Seoul, Korea. His main research interests include Building Information Modeling (BIM), rule-based design validation, interoperability, information visualization, modular construction, and construction automation. Dr. Lee is the recipient of many awards for excellence in research, papers, and teaching including the Outstanding Research Achievement Award from Yonsei University for 2011, the Excellence in Research Award from the Korea Association of Industry, Academy and Research Institute in 2009, and the Yonsei Best Teacher Award for the years 2006,2007 , and 2011, as well as best paper awards from various conferences and journals from 2007 to 2014 . He has numerous national and international publications, including over 130 academic papers and several books, and holds 16 patents. Dr. Lee is Chief Editor of The BIM and an editorial board member of Advanced Engineering Informatics. He has also been a committee member of the National Science \& Technology Council (NSTC) of South Korea. He is an active member of ISO/TC59/SC13 and participated in the development of ISO 29481, "BIM - Information delivery manual," as well as other standards related to building information.

Ghang Lee<glee@yonsei.ac.kr> email and file management. From research specific to BIM and web-enabled collaboration, as well as Information Technology in AEC generally, we know that technology alone will not create collaborative teams[6][7]. Consequently, to develop teams and management systems that support BIM-based collaboration, there has been an effort in recent years to develop BIM planning execution guidelines and procedures[8].

A BIM execution planning guide, (BEP) developed by the Pennsylvania State University, proposes four steps in developing a BIM execution plan 1) Identify BIM goals and uses, 2) Design a BIM project execution process, 3) Develop information exchange requirements, and 4) Define supporting infrastructure for BIM implementation [8]. We had the students use this guide as they developed BEPs for their global teamwork efforts. In this education project, the BIM execution planning activities tie together the technology strategies with the management and leadership skills.

This paper presents our investigation into how the structure of the term project (team organization, software and task distribution) influenced the learning outcomes (leadership, management and technology competence). In general, we sought to teach students to interact in a virtual environment with their team members using models, drawings and documents. Through this process they learned how the virtual environment technologies both support and hinder the discovery and resolution of technical issues in the design and construction planning tasks. Specifically, to help support and coordinate management competence and technology mastery learning goals, we explored using BIM execution planning activities to help the students organize their teams' goals, create shared ownership, plan information exchanges and create meaningful distributed team interactions.

We first review the literature as it pertains to teaching distributed team collaboration in virtual environments. Then, as a case study, we present the 2015 global team project: the team structure, the problem description, and the school specific assignments. We then present student reflections from a post-project survey conducted at two of the participating universities and conclude with a summary of learning assessment and faculty reflection.

\section{Literature Review}

When designing collaboration workspaces for complex interdependent tasks, technologies must support frequent interactions and meetings[6], participant awareness of and access to the design work of others[9], as well as the real-time activities that enhance the work of co-located designers. These include informal, 
spontaneous, or coincidental exchanges of information[10], what Dossick and Neff have termed "messy talk"[7]. Real time interaction has been found to be critical for timely and rapid iterative design, brainstorming, and problem-solving tasks[5]. In studies of interactive workspaces, Leicht et al. found that stages of problem solving seen by AEC industry members as being the most important for collaboration were the same stages found to be the most valuable for interacting with display or physical media[11].

However, as international collaboration increases in $A E C[12][13]$, project participants are challenged to make these real-time interactive connections. Chinowsky and Rojas proposed the following four principles as the key success factors in geographically dispersed team ("virtual team") projects: 1) Modify processes to accommodate remote collaboration; 2) Focus on the completion (final goal) of the project, not on detailed tasks; 3) Establish protocols and standards for sharing data; and 4) Empower teams to make independent decisions[14]. Furthermore, Kovacic and Muller identified the early involvement of stakeholders, simultaneous collaboration, and transparency in communication and information as success factors in integrated and collaborative design processes[15].

Collaboration online with distributed team members is becoming very common in practice, but it is not something that comes naturally to most people. Students in AEC fields need to develop the skills identified by Chinowsky and Rojas, Kovacic and Muller, and Leicht related to participating and leading distributed multidisciplinary teams in design and construction planning contexts[16]. As teamwork is a social process of developing a shared understanding amongst individuals, these skills are best developed in experiential projectbased settings[17].

Inclusion of BIM tools in project management classes within AEC disciplines enables students to work on more complex projects and increases the opportunity to learn different project management methods in a single project experience[18]. There have been several efforts to integrate BIM and collaborative design in AEC education. Ibrahim and Rahimian compared and analyzed the differences between computer-aided design and manual sketching tools in architectural design studios composed of 38 novice designers (second-year university students). They found that manual sketching tools were helpful in expressing students' concepts, but were limited in helping students understand the complicated design problems[19]. Peterson et al. reported lessons learned from a BIM-supported project management class to include that BIM-based project management tools helped students understand project documents and details in a structured way and also understand the complex relationships amongst as well as the impacts of changes on the project scope, time, and cost[18]. Elinwa and Agboola stressed the importance of a virtual design environment in education as a way to break through cultural boundaries[20]. However, all these efforts were limited to a class project within one university. In this paper we report on an educational project with distributed team collaboration competency learning goals, supported by BIM and virtual team technologies that encompasses a global design studio project involving seven universities on three continents. We used BIM to help virtual teams organize and communicate their work, while learning to lead and manage within these virtual team experiences.

\section{Participating Universities}

The global virtual studio project began in 2009 by researchers at Columbia University as a global studio project with Aalto University, IIT Madras and the University of Twente[3]. In 2015, the number of participating universities increased to seven: namely, the Indian Institute of Technology Madras (IIT) in India, National Cheng Kung University (NCKU) and National Taiwan University (NTU) in Taiwan, the University of Twente (UT) in the Netherlands, the University of Washington (UW) and Washington State University (WSU) in the US, and Yonsei University (YU) in South Korea. Four of the universities were in Asia, two in North America, and one in Europe.

The IIT had 42 undergraduate students, while UT had 20, UW had 24, WSU had 24, NCKU had 17, and Yonsei had 50 undergrad and graduate students who participated on project teams. The programs varied across the schools from $2^{\text {nd }}$ to $4^{\text {th }}$ year undergraduate classes to Masters level classes. For example, students from UW were in a Masters level class and those from NCKU were second-year undergraduates. The students were divided into 12 teams, each included between one and four students from each of the seven universities. Each school was responsible for a school-specific module (Fig. 1), and the team project was a combination of the school-specific modules. Some universities participated in the global project as part of a BIM course, project management course, special project or as a design studio class.

This paper reports case study observations of students and faculty reflections from UW and $\mathrm{YU}$, along with results from a survey distributed to the two groups of students. Students from UW consisted of students primarily from the department of construction management and civil engineering. Students in the UW cohort had a variety of industry experience and 
represented several nationalities (e.g., domestic students from the US as well as international students from India, Taiwan, and the Middle East). This term project occurred in the last 5 weeks of their 10-week winter quarter class. YU participated in the global project as a two-week warmup project of an $4^{\text {th }}$-year undergraduate capstone design studio at the beginning of a spring semester. The YU students were from the Department of Architectural Engineering. In South Korea, architectural (engineering) students learn structural engineering, building construction \& construction management, mechanical, electrical, plumbing (MEP) design, energy simulation, and sustainable design as well as general architectural design and theory. Except for one student from Malaysia, all the other students were Korean. In the capstone design project at $\mathrm{YU}$, each student played the role of either architectural designer, structural engineer, sustainable building designer, cost estimator, or scheduler. However, during the two-week global project, all YU students participated in the project only as schedulers in order to align each school with one technical role. More details on the role of each school in the global project are described in the following sections.

\section{Project Description}

The learning objectives of the project were:

- To help students increase their understanding of the practice of distributed team project management and use BIM execution planning in the context of a global team, and

- To expose the students to advanced tools for project collaboration and planning

The team project assignment asked the students to work together to design "rapid house" construction in India and Taiwan, create construction plans (schedules and estimates), and present their work. In the virtual world environment, students from each university could shared constraints. Virtual world tools, Sococo and Virtual BIM Reviewer (VBR) were used. Sococo is a commercial online meeting tool[21], while VBR is an avatar-based online BIM review tool developed by NTU.

A subteam consisted of students from three schools and a group of students from each school played the role of either designer/modeler, cost estimator, scheduler, or four-dimensional (4D) modeler/ project manager. The students were expected to work locally using the data received from the other team members and share and discuss their work in the virtual world together as a team. They were encouraged to meet together as often as possible and asked to consider using tools like GoogleDocs to jointly edit the materials in real time while sharing the document on the Sococo displays.

\section{Design Problem Description}

Practically no meeting time slots existed that would allow the full cohort from all seven universities to meet without hardship (e.g., team members being up in the middle of the night). The teams were divided into two subteams to reduce time-zone problems and to encourage real time communication between team members. Subteam 1 worked on a site in India, while subteam 2 worked on a site in Taiwan. Both subteams were asked to explore different construction methods (including: site built, panelized and modular systems) for rapid housing reconstruction after a disaster. Figure 1 shows the teams' structure. One of the advantages of global teams was the ability to share different industry experience and perspectives, while the challenge was for the team members to understand local conditions. For example, Subteam 1 had local knowledge from the Indian partners with input from European partners who generally are very familiar with modular construction, along with experience with panelized construction methods from the American team members. However, the technical knowledge of various team members varied greatly, so cross-country technical learning was not consistent across all teams.

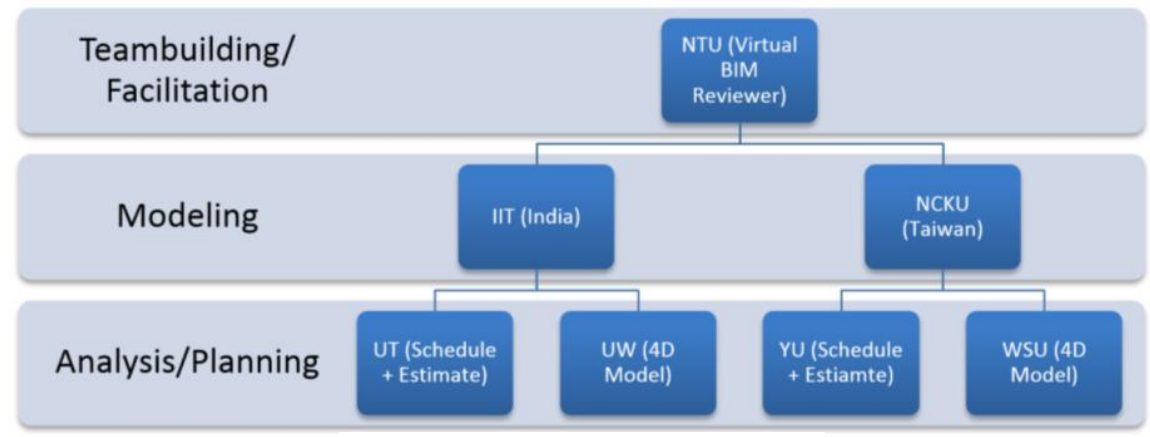

Figure 1. 2005 Project Team Structure

share their work on a virtual team "wall" and discuss
Subteam 1 was tasked with the design of 50 houses ausMT Vol. 5 No. 3 (2015) 
in India that could be quickly deployed as temporary and permanent structures following an earthquake or flood. For example, in 2013, 85,000 people in India's Ganjam District were evacuated due to floods[22] but reconstruction took many months and in some cases years. Similarly, subteam 2 was asked to design 50 houses in Taiwan as a replacement for the houses destroyed by an earthquake. This exercise focused on evaluating the use of offsite and modular construction to achieve rapid mass housing reconstruction. For both sites, the house specifications included:

- $\quad$ The average area of each house is $500 \mathrm{ft}^{2}(46.5$ $\mathrm{m}^{2}$ ).

- The house should be used for permanent residence (i.e., feel like a home).

- The cheaper, the better.

- The faster you can build, the better.

- The building should be aesthetically and functionally satisfactory. The building should be environmentally friendly. India experiences rolling blackouts.

The teams were asked to explore two options: 1 ) site built/panelized and 2) modular (e.g. wet walls or full room) and to compare the differences between the designs developed based on the two methods.

\section{School Specific Modules}

The various schools operated on different schedules and emphasized different educational focuses. For example, UW uses a quarter system, while YU uses a semester system with a new term beginning in March after a long winter break. In other schools, the new quarter/semester began sometime in January or early February. The education focus at UW, WSU, and UT emphasized construction management while IIT and NCKU focused more on design education and YU teaches architectural design, structural engineering, and management. Students from each school were assigned to a specific task depending on their school calendar and education program. UW and WSU, which began in January, led BIM execution planning and 4D modeling. IIT and NCKU, which also started in January and had design students, led design and modeling. UT and YU, which respectively started in February and March, led scheduling and cost estimation. This assignment also followed the order of dependencies between activities: BIM execution planning first, then designing/modeling, then scheduling and cost estimation, and finally 4D modeling (Table 1).

As illustrated in , subteam 1 included students from IIT, UW and UT. IIT provided a house design in a three dimensional (3D) BIM, design guidelines and information on the region, cultural preferences, and specifications for what constituted appealing housing (Figure 2). Meanwhile, UW students provided a BIM execution plan. Figure 3, Figure 4, and Figure 5 show examples of collaboration strategies UW students included in their BIM execution plans. UT students joined the collaboration three weeks prior to the final deadline, and focused on analyzing the design options as they related to schedule and cost estimation. UW students further analyzed the India context-specific design and planning with 4D models (Figure 6 shows a snapshot of one of the 4D models). Figure 7 shows an example of a workflow in Subteam 1 from one of the UW student team's BIM execution plans.

Subteam 2 included NCKU, YU and WSU students. NCKU provided the design guidelines and region-specific information, site information and descriptions of the types of housing commonly found in that area. NCKU took the lead on 3D model development. YU joined the project last when the prefabrication workshop began in early March to coincide with the start of the new YU semester. YU students worked on cost and scheduling issues related to panelized and modular systems in Taiwan while WSU students created 4D models for analysis.

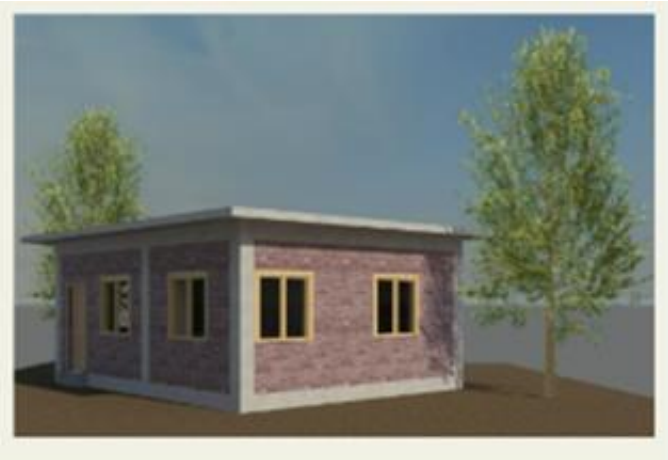

Figure 2. 3D models provided by IIT for both panelized and modular systems

mechanical and plumbing design as well as construction 


\begin{tabular}{|l|l|l|l|l|}
\hline $\begin{array}{l}\text { FILE } \\
\text { LOCATION }\end{array}$ & $\begin{array}{l}\text { FILE STRUCTURE } \\
\text { NAME }\end{array}$ & FILE TYPE & SECURITY & UPDATED \\
\hline Google Drive & $\begin{array}{l}\text { ROOT PROJECT } \\
\text { FOLDER }\end{array}$ & FOLDER & Invite Only & ONCE \\
\hline & $\begin{array}{l}\text { BIM EXEC. PLAN } \\
\text { FOLDER }\end{array}$ & FOLDER & NO & ONCE \\
\hline & MODELS FOLDER & FOLDER & NO & ONCE \\
\hline & PEN FOLDER & RVT & NO & $\begin{array}{l}\text { AS MODEL } \\
\text { EVOLVES }\end{array}$ \\
\hline & $\begin{array}{l}\text { MEETING } \\
\text { MINUTES FOLDER }\end{array}$ & FOLDER & NO & $\begin{array}{l}\text { FO MOLLEL } \\
\text { EVOLVES }\end{array}$ \\
\hline
\end{tabular}

Figure 3. Electronic communication procedure.

\begin{tabular}{|l|l|}
\hline \multicolumn{2}{|l|}{ FILE NAMES FOR MODELS SHOULD BE FORMATTED AS: } \\
\hline DISCIPLINE - PROJECT NUMBER - BUILDING NUMBER.XYZ (example: ARCH-GTA.2015.03-BL001.xyz) \\
\hline ARCHITECTURAL MODEL & ARCH- \\
\hline CIVIL MODEL & CIVIL- \\
\hline MECHANICAL MODEL & MECH- \\
\hline PLUMBING MODEL & PLUMB- \\
\hline ELECTRICAL MODEL & ELEC- \\
\hline STRUCTURAL MODEL & STRUCT- \\
\hline ENERGY MODEL & ENERGY- \\
\hline CONSTRUCTION MODEL & CONST- \\
\hline COORDINATION MODEL & COORD- \\
\hline
\end{tabular}

Figure 4. File naming procedure.

\begin{tabular}{|c|c|c|c|c|}
\hline CHECKS & DEFINITION & $\begin{array}{l}\text { RESPONSIBLE } \\
\text { PARTY }\end{array}$ & $\begin{array}{l}\text { SOFTWARE } \\
\text { PROGRAM(S) }\end{array}$ & FREQUENCY \\
\hline $\begin{array}{l}\text { VISUAL } \\
\text { CHECK }\end{array}$ & $\begin{array}{l}\text { Ensure there are no } \\
\text { unintended model } \\
\text { components and the } \\
\text { design intent has } \\
\text { been followed. }\end{array}$ & DESIGN TEAM & $\begin{array}{l}\text { REVIT, } \\
\text { VIRTUAL BIM } \\
\text { REVIEWER }\end{array}$ & WEEKLY \\
\hline $\begin{array}{l}\text { CLASH } \\
\text { DETECTION }\end{array}$ & $\begin{array}{l}\text { Detect problems in } \\
\text { the model where two } \\
\text { building components } \\
\text { are clashing including } \\
\text { soft and hard. }\end{array}$ & DESIGN TEAM & NAVISWORKS & $\begin{array}{l}\text { DD, CD AND } \\
\text { TURNOVER }\end{array}$ \\
\hline $\begin{array}{l}\text { VERSION } \\
\text { CONTROL } \\
\text { CHECK }\end{array}$ & $\begin{array}{l}\text { Ensure that the } \\
\text { software used to build } \\
\text { model is in sync for all } \\
\text { the participants on the } \\
\text { project }\end{array}$ & ALL & $\begin{array}{l}\text { REVIT, } \\
\text { NAVISWORKS }\end{array}$ & MONTHLY \\
\hline $\begin{array}{l}\text { MODEL } \\
\text { INTEGRITY } \\
\text { CHECKS }\end{array}$ & $\begin{array}{l}\text { Ensure that the model } \\
\text { continues to follow } \\
\text { design intent } \\
\text { throughout the design } \\
\text { and review process } \\
\text { while conducting } \\
\text { constant checks to } \\
\text { identify that the } \\
\text { integrity is not } \\
\text { compromised due to } \\
\text { any additional } \\
\text { components. }\end{array}$ & DESIGN TEAM & $\begin{array}{l}\text { NAVISWORKS, } \\
\text { VBIM REVIEWER }\end{array}$ & MONTHLY \\
\hline
\end{tabular}

Figure 5. Quality control check.

NTU students oversaw both subteams and focused on team building, meeting facilitation, progress scheduling and model review. They worked to bring the models into the VBR for the teams to view and study the models in a virtual world environment. Only some of the teams accomplished this as the VBR was still under development.

\section{Schedule}

Due to the constraints imposed by different academic calendars (Table 1), we planned a phased start with NTU, IIT, NCKU, UW, WSU starting the project ausMT Vol. 5 No. 3 (2015) 
together in January, then UT joining mid-February and YU joining for the last two weeks for the workshop. The purpose of the phased start was to give IIT and NCKU enough time to develop models that the other schools could then use for model-based estimating, 4D modeling and virtual world viewing.

The prefabrication workshops were the focus of intensive team interactions. In week 1 the students were instructed to develop alternatives and ideas and develop estimates, schedules and 4D models. Week 2 work included model refinement and final analysis. For the final analysis, the students were instructed to finish with an all-hands meeting to discuss and compare subteam 1's work (India site) with subteam 2's work (Taiwan site) and create matrix of strengths and weaknesses of construction methods (site, panelized and modular).

\section{Student Reflections and Learning Assessment}

At the end of the term project, students from UW and $\mathrm{YU}$ were given a survey to capture their reflections on the global team experience. The survey asked the students to specify their satisfaction level in a seven point Likert scale question format. In addition, the survey asked students several questions in an open ended format with regards to the means and methods of their communication, the meeting schedule, things they liked about the global team project, difficulties experienced, lessons learned, and suggestions for the future classes (Appendix A).

This section presents analysis of the survey results as well as the feedback provided by students throughout the project and their final presentations. Tables 2 through 6 show the survey results as reported by each team. In Tables 2, 3, 4 and 6 we differentiate between shared findings (shown in orange and grey) with those of each school (YU shown in blue and UW shown in purple).

Overall satisfaction of YU students was 4.8 out of seven, while UW students had a slightly average higher satisfaction level of 5.5 out of seven. What both student groups liked most about this global design project was that they had a chance to work with people in other regions. They learned how to work collaboratively to solve problems and overcome obstacles such as time and

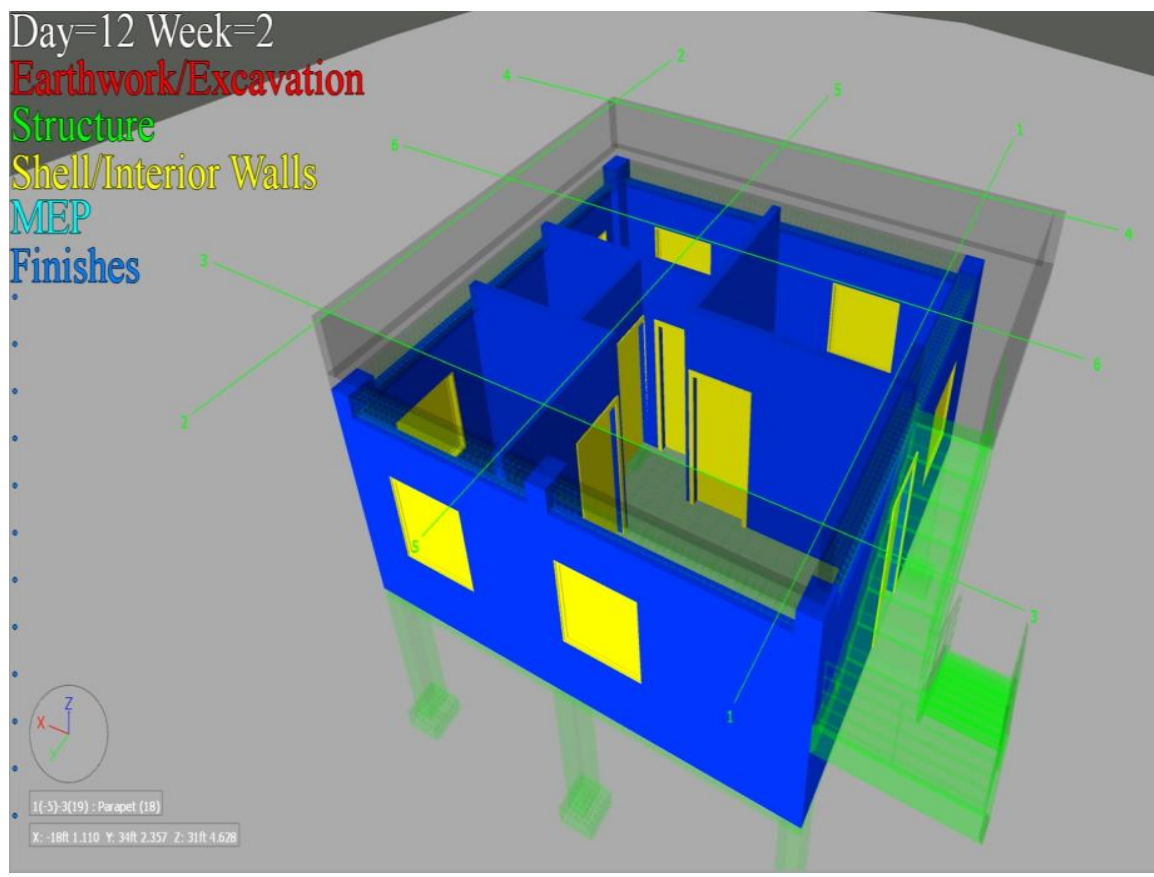

Figure 6. UW team 4D model of a pre-cast model.

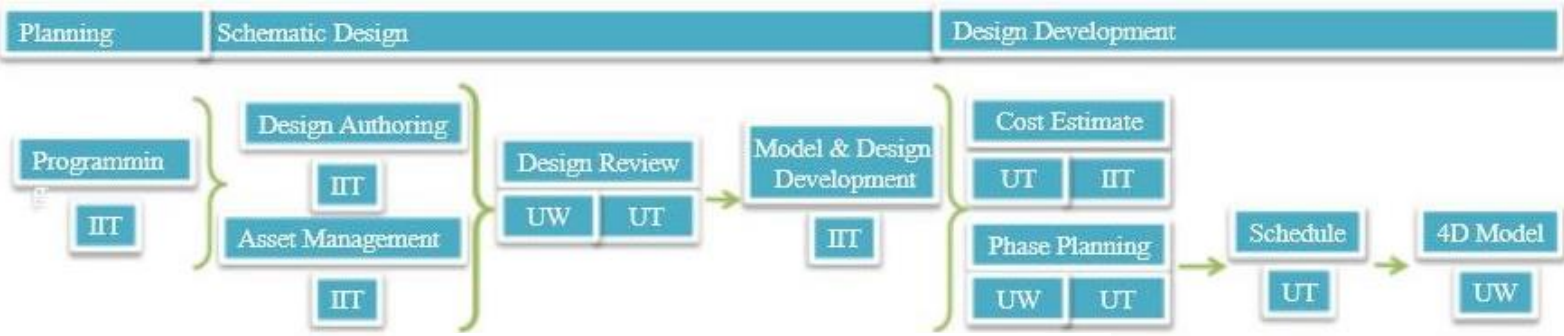

Figure 7. Project workflow in subteam 1. 
language barriers. They enjoyed the collaborative effort because it provided a unique opportunity to learn new construction techniques from around the globe. The project familiarized them with other phases of design and construction outside their own discipline and scope of work. They also cited the course for giving them room to think and work creatively and the opportunity to use multiple software tools. The students reported that they learned how BIM is/should be used in real life, and students stated that BIM can be best learned through team assignments.

The faculty observed increased engagement in class when the global teams were underway. The buzz in the room was palpable as students exchanged stories, software tips and status of their projects. Students from both UW (6 of 12 teams) and YU (9 of 12 teams) reported that the new experience-collaboration with team members from around the globe-was a positive experience and contributed to their learning. "How to work collaboratively" and "learning new tools" were also noted as positives by both UW and YU teams. As UW teams were in charge of the BIM execution planning and participated in the global team project from the start of the project, the UW responses listed a variety of other positive learning outcomes such as understanding applications of BIM execution plan in a "real life" setting (see Table 2). The factors contributing to the students' learning included learning how to use new tools and collaborate effectively.

Difficulties with the experience, on the other hand, fall into three categories (Table 3): Project, Communication and Tools. Nine out of the 12 teams reported that there disparities in project scope and understanding of the deliverables. In addition, students reported challenges when the schedules and deadlines for schools did not align to the team's internal information exchange requirements. For example, many of the UT students did not provide scheduling information to UW teammates until the end of the second week when the UW reports were due, giving them very little time to complete their 4D models.

\section{Learning Outcomes}

Learning outcomes are summarized in Table 4. Eleven of the twelve teams reported that they learned about the challenges of working in a distributed team. The other lessons listed were split between the YU experience and the UW experience. While the UW students took on leadership roles in their subteam through BIM execution planning, the YU students were last to join their team and found the information exchange and team work full of challenges and lessons.

The multifaceted learning goals of this term project include the development of leadership, management, and technology skills, along with expertise in Table 4 applied design and construction. Of the lessons shown in four relate to leadership, nine relate to management, seven encompass BIM technology and planning competencies, while two cover skills related to design and construction. This analysis suggests that the learning objectives for the term project were generally met.

\section{Learning about Distributed Team Project Management}

students better understand practices of distributed team project management, primarily through BIM execution planning. The students from both universities mentioned the importance of collaboration in overall project success, as well as various lessons they learned as to how to collaborate in global team projects. YU students emphasized the importance of early involvement of team members in collaboration. They were the last to join the teams as their spring semester started right at the beginning of the 2-week workshop period and were thus unable to participate in workshop planning.

Being in charge of developing the 4D model and BIM execution plan, UW students paid more attention to specific techniques used for collaboration in global teams and thus had a better understanding of their importance. In the survey, the UW students mentioned improved understanding of compromising, BIM execution planning, use of a facilitator, team building with one shared goal, constant communication (even on obvious matters), 3D and $4 \mathrm{D}$ representation of data, time allocation, team members' onboarding process, setting regular meeting times and keeping a memo of each meeting.

Furthermore, team members expressed that team building, expressing expectations on communication frequency, and designating an individual to follow up with assigned tasks helped overcome issues arising from the passive participation of various team members.

The survey results in both student groups showed that the students gained insight into the difficulties of collaborating in global teams. For the UW team, the global team project provided a good environment to juxtapose various practices of collaboration and to develop an understanding of how some techniques might work better within global teams. One of the students, for instance, stated: "At the beginning of the quarter I thought (and wanted) everyone to meet up at the same time so that we would all be on the same page but that was difficult to manage and very little got done. I now realize that we usually accomplish much more when there are fewer people present at the meetings - at least one person from each school who could then pass on what we discussed to their other classmates." Several teams reported this type of learning through experience. 
Learning about web-based and BIM-based collaboration technologies

The second learning objective of this term project was to expose the students to advanced tools for project collaboration and planning. In their survey responses, YU students highlighted the importance of knowing how to use the software tools. As demonstrated in , each member of subteam 2 spent an average of 150 minutes using the virtual team collaboration platform Sococo (we did not receive enough information from UW team to analyze communication means on subteam 1). As reported by YU students, some teams spent only about an hour on a single conference call while the other teams had multiple conference calls. The Virtual BIM Reviewer server was not able to host the teams, so this tool went underutilized throughout the project. Students also used Dropbox and Facebook Messenger, but most communication took place by email. One of the reasons that students used online real-time meeting tools less than expected was that the online meeting tools were slow and unstable, especially when working with participants in countries with low internet speed. This finding confirms that a reliable online meeting tool is a key to the active communication among global project team members.

Reported challenges with software tools and data exchange ranged from interoperability and version incompatibility issues to having different preferences, and limited access to some software tools in certain schools. Some team members used a specialized tool such as the Open BIM Server and asked that their partners provide data in a specific format. However, these formats were not well understood nor were they supported by the tools used by the other team members. Even when different team members used the same tool, if they used different versions the model could not be exchanged bidirectionally. The UW students suggested that these problems could have been avoided if all team members had joined the project early on and jointly participated in development of the BIM execution plan together, because BIM execution planning would allow the team to discuss their different software packages and determine (and perhaps test) how to best exchange data between their systems. Regardless of early involvement, two weeks was insufficient time to identify and resolve data exchange problems. Students generally felt that more time should be given for this type of global team assignment.

For example, the UT students joined subteam 1 somewhat later in the planning stage and were not initially involved in the BIM execution planning. They thus struggled with information exchange and needed time to reconcile data needs and formats. The students also realized that participation of all team members in development of the BIM execution plan would have been helpful in that all team members would have developed a sense of ownership for the document and thus would been more consistent in execution.

Due to unclear role definitions, subteam 2 failed to develop or share a BIM execution plan among team members. The two-week prefabrication workshop was simply insufficient to allow students to identify and resolve data exchange problems. In future iterations of this assignment, students recommended that, to maximize the use of these two weeks, the instructors, who know which software tools are available in their institutions, should establish a data exchange protocol in advance since it is practically impossible for students on vacation to join the project early. Still, with this course planning, data exchange problems should be expected, even when students are provided with a predefined data exchange protocol. In our experience with this type of course specifically, and BIM coursework in general, new technical issues emerge each year with software updates.

\section{Global Team Challenges}

The challenges students experienced with regards to communication were mostly caused by time zone coordination resulting in missing meetings, passive participation, and comprehension issues caused by disparities of regional accents and audio latency. While some teams did not find accents a challenge, others chose to rely on text chat rather than voice to increase comprehension. One team reported that the Taiwanese students had particular trouble understanding the accents of the students from India. An American student reported that he simply would restate what the Indian students said and this greatly helped the Taiwanese students understand the message. Different teams dealt with this challenge in different ways. Both student groups mentioned that using e-mail and text massages helped them overcome the accent problem to some extent.

Another linguistic challenge was noted by the $\mathrm{YU}$ students who also reported that models and documents contained regionally-specific terms which presented an obstacle for collaboration. They reported using on-line translator tools such as Google Translate to translate regional words used in documents and models.

Another common challenge with global team collaboration is time zone changes. There were two challenges with time. First was getting all of the team members to understand the time they wanted to meet. Working across the international dateline meant that some UW team members logged in the day "after" the meeting was scheduled, not realizing that the time zone differences would make the meeting the evening before in the US time zone as compared to the time and date in Asia. An additional challenge to student team 
coordination was presented by the occurrence of "daylight savings" in the US during the two-week workshop. Some teams appointed specific facilitators to coordinate meeting times, specifying local times for each participant while scheduling meetings. While initial meetings presented some confusion, the facilitators quickly resolved the issues and helped participants use online calendar systems to specify the time in each location.

The difficulties noted in this section had some negative effects on the quality of project outcomes as well as ability of the team members to meet the project requirements. Initially we had asked students to analyze and compare the costs and schedules of houses built using the site-built vs. modular construction methods, but few teams were able to complete this assignment. Through this global project, however, students did become familiar with the difficulties of working with geographically dispersed teams and the importance of clearly defined and shared project goals, roles, and deliverables, as well as other key collaboration techniques. As one of the UW teams noted in its final presentation "If our goal is to experience virtual world, such an integration is feasible. [However,] If our goal is to deliver a high-quality and accurate product (for a graduate level construction course) this integration is challenging!"

\section{Curriculum Refinement}

Besides the many achievements of this experience, the students also reported on many challenges they faced and made suggestions for improvements (Table 6). The challenges they experienced helped improve their understanding of how to collaborate and use software tools within global teams, and also provided contributing faculty with insights for improving course design.

In the next iteration of this joint term project, teams will be divided into two sub teams to engage in sequential interaction, where Subteam 1 meets February to March, and then passes on their findings to Subteam 2 who will work from March to April. In this way, we will create smaller teams with longer interactions that accommodate the various school schedules and objectives.

Finally, students reported some project characteristics that hindered their collaboration. The most important issue cited by both student groups was related to divergent understandings of project goals, final deliverables, and work scope. For example, students were asked to develop two designs: a site-built design and a modular design. However, several team members in charge of design developed only one design without details required for cost estimation and scheduling assuming that the other team members in charge of cost estimation or scheduling would develop detailed designs for the two models. To overcome this issue, the students suggested the course description and handouts for all participating universities be the unified, with deliverables and deadlines for all teams clearly specified.

Another major issue reported by both teams was late arrival of the scheduling teams. YU students, who could only work on the project for the last two weeks, felt that two weeks was too short a time to acquaint themselves with other students and also to accomplish the project goals, especially because there was only a small window for communication with the other team members due to time differences. Likewise, the UW team expressed frustration over the late schedule handover from UT who also joined the collaboration late, leaving UW with tight deadlines for developing their 4D models. Subteam 1 also did not have time for the review, feedback, and correction cycle. Some of the UW students proceeded to develop their own schedule earlier to have enough time to develop their 4D model.

Retrospectively, UT and YU were involved in this project only for two weeks. In terms of the work sequence, it seems more appropriate for UT and YU to work on 4D modeling than scheduling and cost estimation. An effective means of dividing students into subgroups, and assigning roles and responsibilities to the teams is needed to overcome difficulties resulting from divergent academic calendars. For example, 4D modeling can be assigned to the last comers like YU and UT and scheduling and cost estimation can be assigned to teams that can join the project early.

Faculty members might also investigate the possibility of offering the course at the beginning of the academic year (rather than second semester/quarter) to maximize overlap, although this may be challenging for the current collaborating universities.

The last project-related issue that both groups reported as challenging was the design teams' lack of expertise in incorporating regional data (construction methods, costs, etc) into the design and development of detailed 3D models for association with schedule and development of cost estimates and the 4D model. The shared designs had many errors (e.g., a room without a door) and lacked much basic information (e.g., missing materials information and missing building elements such as foundations). This was mainly due to the fact that the students in charge of design were sophomore level and did not have enough knowledge to design a house. Furthermore, the different levels of design and construction knowledge made it very difficult for students to communicate with each other. A lesson learned is that participating students should be at least $4^{\text {th }}$ year undergraduates or graduate students to be able to effectively work together and achieve a realistic outcome 
from such a project.

\section{Findings and Conclusions}

Although this exercise was a small-scale short-term class project, students experienced difficulties and challenges associated with real global projects and learned concepts and skills related to global team project management as well as virtual collaboration and BIM software tools. They emerged from the experience better prepared in terms of their expectations for managing professional global projects. Both student groups gained a better understanding of the importance of shared goals in global construction projects, the need to involve all team members in BIM execution planning, working with reliable communicating tools, and clearly defining work scope and deadlines for all team members.

The students identified the following leadership and management techniques as critical success factors for global team projects: Collaboration and communication skills with people in other regions, clearly defined and shared project goals, early participation by all team members, active participation and communication between team members, early and collaborative development of a BIM execution plan, and functional knowledge of BIM tools. Specifically, students learned how BIM execution plans could help them understand large-scale long-term projects and how early and collaborative development of a BIM execution plan could help motivate team members to proactively participate in the project by building a sense of ownership.

The exercise had lessons for coordinating faculty members as well. These include the need to clearly define project team roles and responsibilities, incentives for students to participate and collaborate, clear guidelines for modeling, deliverables, and data exchange, and maximizing time overlap between the academic calendars of participating universities.

\section{Acknowledgment}

We are deeply grateful to our collaborators in the global team project: Prof. Jesse Kang, NTU, Prof. JiinSong Tsai, NCKU, Prof. Ashwin Mahalingam, IIT-Madras, Prof. Timo Hartmann, UT, and Prof. Anne Anderson, WSU. We would also like to thank all of the students who participated in the 2015 global team exercises this year. 


\begin{tabular}{|c|c|c|c|c|c|c|c|}
\hline Subteam & & \multicolumn{3}{|c|}{ Subteam 1} & \multicolumn{3}{|c|}{ Subteam 2} \\
\hline Week of & NTU & IIT & UW & UT & NCKU & WSU & YU \\
\hline 05 Jan 15 & Break & Break & & Break & Break & Break & Break \\
\hline 12 Jan 15 & Break & Break & & Break & Break & & Break \\
\hline 19 Jan 15 & \multirow{6}{*}{$\begin{array}{c}\text { Development } \\
\text { and } \\
\text { Maintenance of } \\
\text { the Virtual BIM } \\
\text { Reviewer }\end{array}$} & & & Break & & & Break \\
\hline 26 Jan 15 & & \multicolumn{2}{|c|}{ BIM Execution Planning } & Break & \multicolumn{2}{|c|}{ BIM Execution Planning } & Break \\
\hline 02 Feb 15 & & Modeling & & & Modeling & & Break \\
\hline 09 Feb 15 & & Modeling & & & Modeling & & Break \\
\hline 16 Feb 15 & & \multicolumn{5}{|c|}{ Virtual Team Training and Workflow planning } & Break \\
\hline 23 Feb 15 & & \multicolumn{2}{|c|}{ Finalize Team Assignments } & Break & \multicolumn{2}{|c|}{ Finalize Team Assignments } & Break \\
\hline $\begin{array}{c}02 \text { Mar } 15 \\
\text { (Prefabrication } \\
\text { Workshop) }\end{array}$ & $\begin{array}{l}\text { Development } \\
\text { and } \\
\text { Maintenance of }\end{array}$ & Modeling & 4D modeling & $\begin{array}{c}\text { Scheduling \& } \\
\text { Cost Estimation }\end{array}$ & Modeling & 4D modeling & $\begin{array}{l}\text { Scheduling \& } \\
\text { Cost Estimation }\end{array}$ \\
\hline $\begin{array}{c}09 \text { Mar } 15 \\
\text { (Prefabrication } \\
\text { Workshop) }\end{array}$ & $\begin{array}{c}\text { the Virtual BIM } \\
\text { Reviewer }\end{array}$ & Modeling & 4D modeling & $\begin{array}{c}\text { Scheduling \& } \\
\text { Cost Estimation }\end{array}$ & Modeling & 4D modeling & $\begin{array}{l}\text { Scheduling \& } \\
\text { Cost Estimation }\end{array}$ \\
\hline
\end{tabular}

Table 1. School calendars and assigned activities

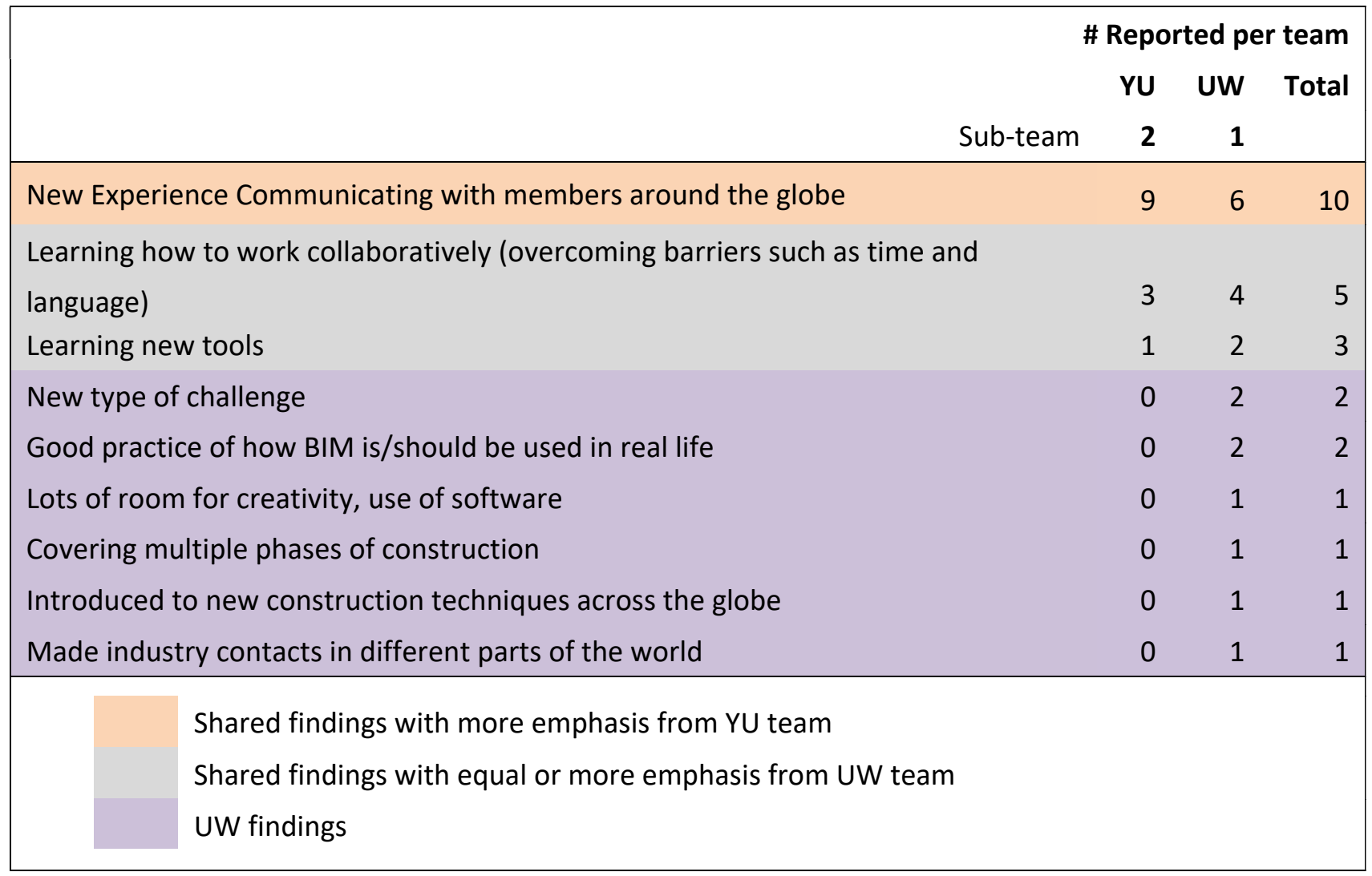

Table 2. Global Team Project factors contributing to learning 


\begin{tabular}{|c|c|c|c|c|c|}
\hline & & & \# Repo & ted pe & r team \\
\hline & & & YU & UW & Total \\
\hline & & Different understanding of project goals and deliverables & 6 & 7 & 9 \\
\hline & & Different schedules/deadlines for each school/ late model hand overs & 2 & 8 & 9 \\
\hline & & Lack of reality and details in the design (and the model) & 6 & 2 & 8 \\
\hline & & Lack of regional data (construction methods, costs, etc.) & 4 & 1 & 5 \\
\hline & 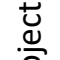 & Models inadequately built for cost estimation and 4D simulation & 2 & 2 & 4 \\
\hline & $\frac{1}{2}$ & Design errors & 2 & 0 & 2 \\
\hline & & Teams didn't follow BIM execution plan & 0 & 2 & 2 \\
\hline & & The cycle of reviews, feedbacks, and corrections on the model was & 0 & 1 & 1 \\
\hline & & Schedule required significant revisions and optimization & 0 & 1 & 1 \\
\hline & & Lack of constraints & 0 & 1 & 1 \\
\hline & & Time zone coordination (Missing meetings) & 2 & 5 & 5 \\
\hline & & English problem (accent) & 3 & 3 & 4 \\
\hline & & Passive participation (missing meetings, deadlines) & 3 & 3 & 6 \\
\hline & & Slow or no response & 3 & 2 & 4 \\
\hline$\stackrel{\mathscr{\Perp}}{+}$ & ᄃ & Model and documents in local languages & 5 & 0 & 5 \\
\hline$\underset{\underline{\underline{u}}}{\overline{\underline{u}}}$ & 突 & Different levels of design and construction knowledge & 4 & 0 & 4 \\
\hline & $\overline{\bar{S}}$ & No English problem & 3 & 0 & 3 \\
\hline & $\stackrel{\varepsilon}{\varepsilon}$ & Sococo problem (delay, system crash, etc.) & 3 & 0 & 3 \\
\hline & & Lack of chance to speak (due to a large number of participants, etc.) & 1 & 0 & 1 \\
\hline & & Absence of coordinators (after week 6th meeting) & 0 & 1 & 1 \\
\hline & & Use of jargon language i.e. in situ, modular, panelized & 0 & 1 & 1 \\
\hline & & Poor file naming & 0 & 1 & 1 \\
\hline & & No significant communication issues & 0 & 1 & 1 \\
\hline & & Interoperability issue (Sococo+3D models) & 4 & 2 & 6 \\
\hline & & Unfamiliarity with tools such as Navisworks (mostly in the beginning) & 2 & 3 & 3 \\
\hline & & Software issues (VBR) & 0 & 5 & 5 \\
\hline & $\overline{0}$ & No problem with tools (Sococo) & 0 & 3 & 3 \\
\hline & & Version incompatibility issue & 1 & 1 & 2 \\
\hline & & Network problem (in India mostly) & 0 & 2 & 2 \\
\hline & & Having different preferences & 0 & 1 & 1 \\
\hline & & Access to tools (Taiwan team did not have access to Navisworks) & 0 & 1 & 1 \\
\hline & & Shared findings with more emphasis from YU team & & & \\
\hline & & Shared findings with equal or more emphasis from UW team & & & \\
\hline & & UW findings & & & \\
\hline & & YU findings & & & \\
\hline
\end{tabular}

Table 3. Global Team Project challenges 


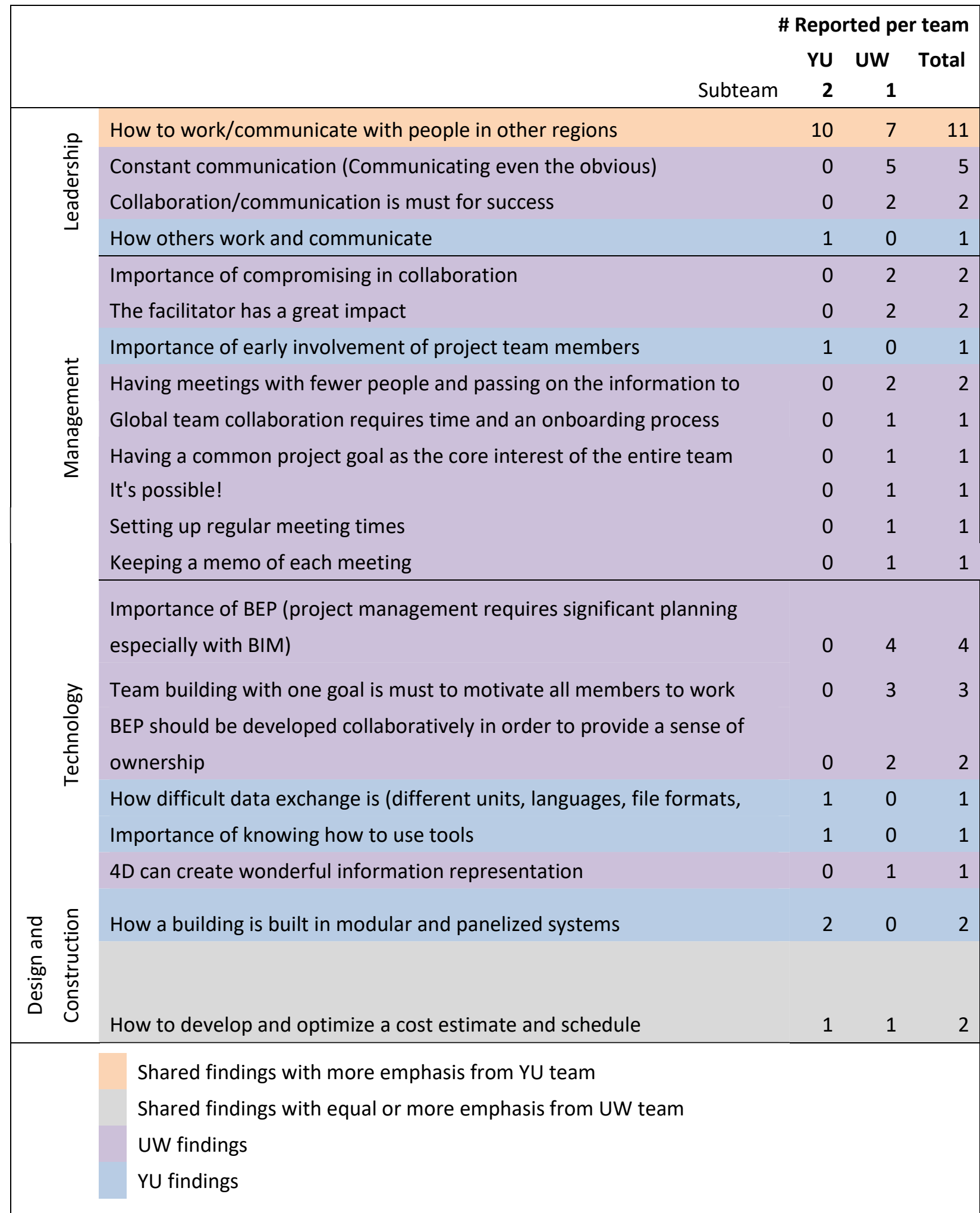

Table 4. Learning outcomes in Global Team Project 


\begin{tabular}{|c|c|c|c|c|c|c|c|c|c|c|c|c|c|c|}
\hline \multirow[b]{2}{*}{ Meetings } & \multirow{2}{*}{$\begin{array}{c}\text { \# of } \\
\text { teams }\end{array}$} & \multirow[b]{2}{*}{ Ave. } & \multicolumn{12}{|c|}{ Team } \\
\hline & & & 1 & 2 & 3 & 4 & 5 & 6 & 7 & 8 & 9 & 10 & 11 & 12 \\
\hline Sococo (min) & 12 & 151 & 120 & 150 & 270 & 240 & 60 & 160 & 180 & 60 & 120 & 60 & 120 & 270 \\
\hline email (Yes/No) & 12 & & 1 & 1 & 1 & 1 & 1 & 1 & 1 & 1 & 1 & 1 & 1 & 1 \\
\hline Dropbox & & & & & & & & & & & & & & \\
\hline (Yes/No) & 2 & & & & & & 1 & & & & & & & 1 \\
\hline Facebook & & & & & & & & & & & & & & \\
\hline Messenger & & & & & & & & & & & & & & \\
\hline (Yes/No) & 4 & & & & & 1 & & & & & & 1 & 1 & 1 \\
\hline GoTo meeting & 1 & & & & & & & & & & & & & 1 \\
\hline
\end{tabular}

Table 5. Meeting duration and communication media in subteam 2

\begin{tabular}{|c|c|c|c|}
\hline & \multicolumn{3}{|c|}{ \# Reported per team } \\
\hline & YU & UW & Total \\
\hline Subteam & 2 & 1 & \\
\hline $\begin{array}{l}\text { Clearly defined and shared project goals, roles, descriptions and schedule (send } \\
\text { out one project description to all schools, identifying responsibilities, etc.) }\end{array}$ & 3 & 6 & 7 \\
\hline Longer project duration & 4 & 0 & 4 \\
\hline Early involvement in the project & 2 & 0 & 2 \\
\hline Active communication/participation & 2 & 0 & 2 \\
\hline Better on-line communication tools & 1 & 0 & 1 \\
\hline Having one goal and one deadline for everybody & 0 & 1 & 1 \\
\hline Smaller collaboration groups & 0 & 1 & 1 \\
\hline Need to make comparison based on same parameters to be useful & 0 & 1 & 1 \\
\hline BIM is better learned in the form of group assignments & 0 & 1 & 1 \\
\hline Shared findings with equal or more emphasis from UW team & & & \\
\hline UW findings & & & \\
\hline YU findings & & & \\
\hline
\end{tabular}

Table 6. Suggestions for future courses

\section{References}

[1] C. Eastman, P. Teicholz, R. Sacks, and K. Liston, BIM Handbook: A Guide to Building Information Modeling for Owners, Managers, Designers, Engineers, and Contractors. Hoboken, New Jersey: John Wiley \& Sons, 2008.

[2] J. Messner, "Offshoring of engineering services in the construction industry," in The Offshoring of Engineering: Facts, Unknowns, and Potential Implications, Washington, D.C.: National Academies Press, 2008.

[3] J. Iorio, G. Peschiera and J. E. Taylor, "Factors impacting usage patterns of collaborative tools designed to support global virtual design project networks," Journal of Information Technology in Construction, vol. 16, no. 14, pp. 209-230, 2011.

[4] S. Comu, J. Iorio, J. Taylor, and C. Dossick, "Quantifying the Impact of Facilitation on Transactive Memory System Formation in Global Virtual Project Networks," Journal of construction Engineering and Management, vol. 139, no. 3, pp. 294-303, 2013. doi: 10.1061/(ASCE)CO.1943-7862.0000610

[5] R. Fruchter, "Degrees of engagement in interactive workspaces," Al and SOCIETY, vol. 19, no. 1, pp. 8-21, 2005. doi: $10.1007 / \mathrm{s} 00146-004-0298-x$

[6] R. L. Daft and R. H. Lengel, “Organizational Information Requirements, Media Richness and Structural Design," Management Science, vol. 32, no. 5, pp. 554-571, 1986. doi: $10.1287 / \mathrm{mnsc} .32 .5 .554$

ausMT Vol. 5 No. 3 (2015) 
[7] C. S. Dossick and G. Neff, "Messy talk and clean technology: communication, problem-solving and collaboration using Building Information Modelling," The Engineering Project Organization Journal, vol. 1, no. 2, pp. 83-93, 2011.

doi: $10.1080 / 21573727.2011 .569929$

[8] C. Anumba, "BIM Project Execution Planning Guide, Version 2.0," The Computer Integrated Construction Research Group, Pennsylvania State, Planning Guide, 2010.

[9] G. Fischer, "Learning in Communities: A Distributed Intelligence Perspective," Learning in Communities, vol. 2, no.2, pp. 11-16, 2006.

[10] R. E. Kraut, S. R. Fussell, and J. Siegel, "Visual Information As a Conversational Resource in Collaborative Physical Tasks," Hum-Comput Interact, vol. 18, no. 1, pp. 13-49, 2003. doi: $10.1207 / \mathrm{S} 15327051 \mathrm{HCl} 18122$

[11] R. M. Leicht, J. I. Messner, and C. J. Anumba, "A framework for using interactive workspaces for effective collaboration," Journal of Information Technology in Construction, vol. 14, no. 15, pp. 180203, 2009.

doi: http://www.itcon.org/2009/15

[12] M. Shaurette, "International Collaboration: An Emergent Opportunity in Construction Management Education," in proceeding of the 50th ASC Annual International Conference, Washington D.C., March 26-28, 2014.

[13] The Top 250 International Contractors, Troy, MI: ENR, 2014.

[14] P. Chinowsky and E. Rojas, "Virtual Teams: Guide to Successful Implementation," Journal of management in engineering, vol. 19, no. 3, pp. 98-106, 2003. doi: 10.1061/(ASCE)0742-597X(2003)19:3(98)

[15] I. Kovacic and C. Muller, "Challenges for the Implementation of Integrated Design in the Planning Practice," Procedia-Social and Behavioral Sciences, vol. 119, no. 0, pp. 529-538, 2014. doi: 10.1016/i.sbspro.2014.03.059

[16] R. Fruchter, "Dimensions of teamwork education," International Journal of Engineering Education, vol. 17, no. 4/5, pp. 426-430, 2001.

[17] J. D. Bransford, A. L. Brown, R. R. Cocking, and others, How people learn. Washington, DC: National Academy Press, 2000.

[18] F. Peterson, T. Hartmann, R. Fruchter, and M. Fischer, "Teaching construction project management with BIM support: Experience and lessons learned," Autom. Constr., vol. 20, no. 2, pp. 115-125, 2011. doi: 10.1016/j.autcon.2010.09.009

[19] R. Ibrahim and F. Pour Rahimian, "Comparison of CAD and manual sketching tools for teaching architectural design," Automation in Construction, vol. 19, no. 8, pp. 978-987, 2010. doi: 10.1016/i.autcon.2010.09.003

[20] U. K. Elinwa and O. P. Agboola, "Beyond BIM - A Classroom Approach to Virtual Design Education," Procedia-Social and Behavioral Sciences, vol. 83, no. 0, pp. 393-397, 2013. doi: 10.1016/j.sbspro.2013.06.077

[21] "https://www.sococo.com/," Sococo. .

[22] "Floods kill dozens in eastern India - CNN.com," CNN. [Online].

Available:

http://www.cnn.com/2013/10/26/world/asia/indiafloods/index.html. [Accessed: 11-Apr-2015]. 


\section{Global Team Project Feedback Report}

Team \#:

Meetings

\begin{tabular}{|l|l|l|l|l|}
\hline date & $\begin{array}{l}\text { start time-end } \\
\text { lime }\end{array}$ & $\begin{array}{l}\text { Communicalion } \\
\text { method(tools) }\end{array}$ & participants & agenda \\
\hline $2015 / 1$ & & & & \\
\hline & & & & \\
\hline & & & & \\
\hline
\end{tabular}

Satisfaction Level (1-7, 7 being very satisfactory) ( )

Things you liked about the global team project

Difficulties

Project issues

Communication issues

Tool issues

Other issues

Lessons learned

Suggestions for the next-year class

Appendix A. The Survey. 